\title{
Development of Mobile Application for Sustainable Creative Tourism Assessment using Confirmatory Factor Analysis Approach
}

\author{
https://doi.org/10.3991/ijim.v13i06.10500 \\ Chitralada Suphachaimongkol, Chavalit Ratanatamskul ${ }^{(\bowtie)}$, \\ Siriwan Silapacharanan, Patcha Utiswannakul \\ Chulalongkorn University, Bangkok, Thailand \\ dr_chawalit@yahoocom.
}

\begin{abstract}
Creative tourism has received increasing attention. At present, the concept of creative tourism is still in development stage since there are few or no indicators for assessing the potential of creative tourism to area-based sustainable goals. This document aims to introduce the process of mobile application for sustainable creative tourism (SCT) model development using confirmatory factor analysis (CFA) approach. The study was divided into 4 phases. The first phase involved establishing elements, indicators and criteria drawn from some previous studies and the opinions of experts' judgement in this study. Secondly, indicators and criteria were selected by using Delphi technique. Thirdly, the indicators and criteria were confirmed by utilizing CFA, Finally, the prototype of SCT mobile application assessment tool is proposed for SCT in this study, based on CFA. Tools for the study included: 1) structured questionnaire from reviews of literature for interviewing the expert, 2) questionnaire for Delphi techniques among the experts for collecting an opinion about the selection of the indicators, and 3) a questionnaire to assess the possibility of data collection concerning the components and indicators of SCT. 300 samples from creative tourism enterprises from all around Thailand were collected and 253 were responded. Data analysis was conducted by using descriptive statistics and CFA. The study found that SCT model consists of 8 components and 36 indicators. The finding from our research shows that it is eligible to establish the novel SCT assessment indicators. The result of SCT application model is appropriate to develop mobile application for SCT assessment tool.
\end{abstract}

Keywords - Confirmatory factor analysis, Indicators, Mobile assessment tool, Sustainable creative tourism

\section{$1 \quad$ Introduction}

Creative tourism is a new form of tourism which can lead to the potential change in the existing tourism management model and to make a contribution to diversifying and innovating the tourist experience[1]. According to the United Nations Educational and Scientific Organization [2], creative tourism is defined as an opportunity for visi- 
tors to better understand different culture and world by exploring new cultures and local traditions. Creative tourism is based on the authentic experience that will be delivered to the tourist. The specific location where the creative activity takes place can serve as a sign for its authenticity. Tiyaphipat [3] defined creative tourism as an opportunity for visitors to better understand themselves by learning different cultures and traditions. While general tourism may provide opportunities for visitors to enjoy such experiences, it generally does not offer an in-depth encounter with the people and places found during their stay in the country.

The core idea behind creative tourism is to generate real values in local arts, customs, and materials, helping visitors to understand the benefit of these products and services in comparison to mass-produced items. However, implementing sustainable creative tourism is a huge challenge for creative tourism entrepreneurs, which consists of many hurdles[4], including providing entrepreneurs with an understanding of the concept of creative tourism, creating awareness about the value of local art and culture for tourists [5], encouraging better participation between government and local communities in promoting creative tourism, and managing the creative tourism for sustainable development goal. The concept of creative tourism across Thailand has been newly promoted; however, nothing has been concretely implemented to promote this brand of tourism due mainly to a lack of research and understanding about the subject[6]. Currently there are some researches who tried to introduce characteristics and indicators of creative tourism, based on literature reviews[3, 4, 6-9], but there are no empirical statistic research study. Currently, they also no technological tools for assessment of the potential and sustainability of creative tourism practice. Therefore, this research looks into develop and implement the proposed indicators for SCT by using CFA approach. The prototype of SCT mobile application is introduced based on CFA analysis and user requirements.

\section{Conceptual Background and Theory}

The roots of the creative tourism concept go back to the mid-1990s, when a group of researchers and practitioners were looking at ways to enhance the sales of craft products to tourists [10]. The basic aim of the EUROTEX project was to help conserve craft production by marketing local products more effectively to tourists, developing new outlets for craft sales and securing local jobs. It quickly became clear that one of the biggest challenges for craft producers was distinguishing their high-value hand-made products from the cheaper mass produced items. Unless the tourists can appreciate the work and skill that goes into making handcrafted products, they are unlikely to want to pay more for them. These basic ideas became the inspiration for what would later be called "creative tourism". However, Creative tourism does not purport to replace other forms of tourism. It is the only alternative tourism that corresponds with the modern tourists' behavior in travelling that has started to change with exploring the meaning of their surroundings. 


\subsection{Definition of creative tourism}

The term Creative Tourism was "founded" by Crispin Raymond and Greg Richards[11]. Raymond described the origin of creative tourism as he read e-mails from his daughter who visited Thailand, Indonesia and Australia in 1999-2000 and took part in several cultural workshops there. They argued that cultural tourism needed to be more interactive and to allow tourists to more engaging than just visits to temples and museums.

Richards and Raymond thought that there should be a new name for this new trend of tourism where interested tourists can participate and learn cultural activities which would allow a new learning inspiration after the trip is over. Richards and Raymond then named the new form of tourism as Creative Tourism, "tourism which offer visitors the opportunities to develop their creative potential through active participation in courses and learning experiences which are characteristics of the holiday destination where they are undertaken"'[1]. Shortly thereafter, a new definition of Creative Tourism was created at the Santa Fe International Conference on Creative Tourism held in 2008 as "Creative Tourism is a tourism directed toward an engaged and authentic experience, with participative learning in the arts, heritage or special character of a place"[12]. UNESCO [2] defines that travel directed toward an engaged and authentic experience, with participative learning in the arts, heritage, or special character of a place, and it provides a connection with those who reside in this place and create this living culture. In Thailand, The Designated Areas for Sustainable Tourism Administration (DASTA) who responds to promote creative tourism in Thailand gives the definition of creative tourism that "Creative Tourism focuses on conversation, learning, cultural exchange, and believes that it can be the tool to help people understand and value cultural diversity. Furthermore, it reinforces the value of local communities. It also encourages creativity among tourists who can be inspired by their travel experience to improve their life "[13].

\subsection{Creative tourism indicators}

In regard to the literature review of definitions or meanings of the creative tourism and characteristics of the creative tourism, the researchers summarizes the component and indicators of creative tourism are described in table 1.

Table 1. Review of Creative tourism components

\begin{tabular}{|l|l|}
\hline Components & \multicolumn{1}{|c|}{ Deifications and Indicators } \\
\hline Location & $\begin{array}{l}\text { Creative tourism explicitly presented by tourism destinations provides opportunities to } \\
\text { engage with local culture in order to offer a unique experience [14]. The creative tourism } \\
\text { destination (location) includes developed from cultural tourism[3] distinct cultural and/or } \\
\text { natural heritage[15] and interaction with cultural and environment[2] and attractiveness } \\
\text { expression[15]. }\end{array}$ \\
\hline Process & $\begin{array}{l}\text { The process of support and promote for learning and engaging with culture and } \\
\text { heritage[8, 15] to create authentic experience[14] and ability to present meaning of } \\
\text { cultural heritage[4]. }\end{array}$ \\
\hline $\begin{array}{l}\text { Creative activi- } \\
\text { ties }\end{array}$ & $\begin{array}{l}\text { Activities related to creative tourism allow tourists to learn more about the local skills, } \\
\text { expertise, traditions and unique qualities of the places they visit [14] such as cross }\end{array}$ \\
\hline
\end{tabular}




\begin{tabular}{|l|l|}
\hline & $\begin{array}{l}\text { culture exchange promotion [6] interacting with people in community[12] Desire for } \\
\text { more active, engaging experiences[16]. }\end{array}$ \\
\hline Management & $\begin{array}{l}\text { Management of creative tourism such as activity management[9] financial } \\
\text { management[9] basic facilities and infrastructure [9, 17] strategic management[9] co: } \\
\text { operation and community cooperation[9, 16] and promote creativity and innovation [18]. }\end{array}$ \\
\hline $\begin{array}{l}\text { Knowledge } \\
\text { management }\end{array}$ & $\begin{array}{l}\text { The process of creating, sharing, using and managing the cultural and heritage } \\
\text { knowledge of a creative tourism destination such as knowledge transfer[17] Learning } \\
\text { with people [12] advisory with partnership[14] education to community[2] and innova- } \\
\text { tors[7]. }\end{array}$ \\
\hline
\end{tabular}

\subsection{Sustainable tourism indicators}

Sustainability principles refer to the establishment of suitable balance between environment, economic and socio-cultural aspects of tourism development. The United Nations World Tourism Organization (UNWTO, 2005) defines sustainable tourism as a model which responds directly to the needs of visitors while protecting places of interest for future generations. It is therefore important to consider sustainable tourism in all aspects of industry development and management. The purpose of this is to maintain the economic and social advantages brought on by tourism development while at the same time reducing any adverse effects to the natural environment, culture, traditions, and society. This is achieved by maintaining a balance between the needs of visitors and those of the local community. Therefore, it can be deduced that sustainable creative tourism benefits both the present and future economy of a region. UNWTO presents 12 dimensions related to sustainable tourism (see Figure 1) there are:

1. Economic viability

2. Local prosperity

3. Employment quality

4. Social equity

5. Visitor fulfillment

6. Local control

7. Community wellbeing

8. Cultural richness

9. Physical integrity

10. Biological diversity

11. Resource efficiency

12. Environmental purity

However, there are many definition and indicators of sustainable tourism, Table 2, researchers summarize the definition and indicators of sustainable tourism from the reviews of related literature. 


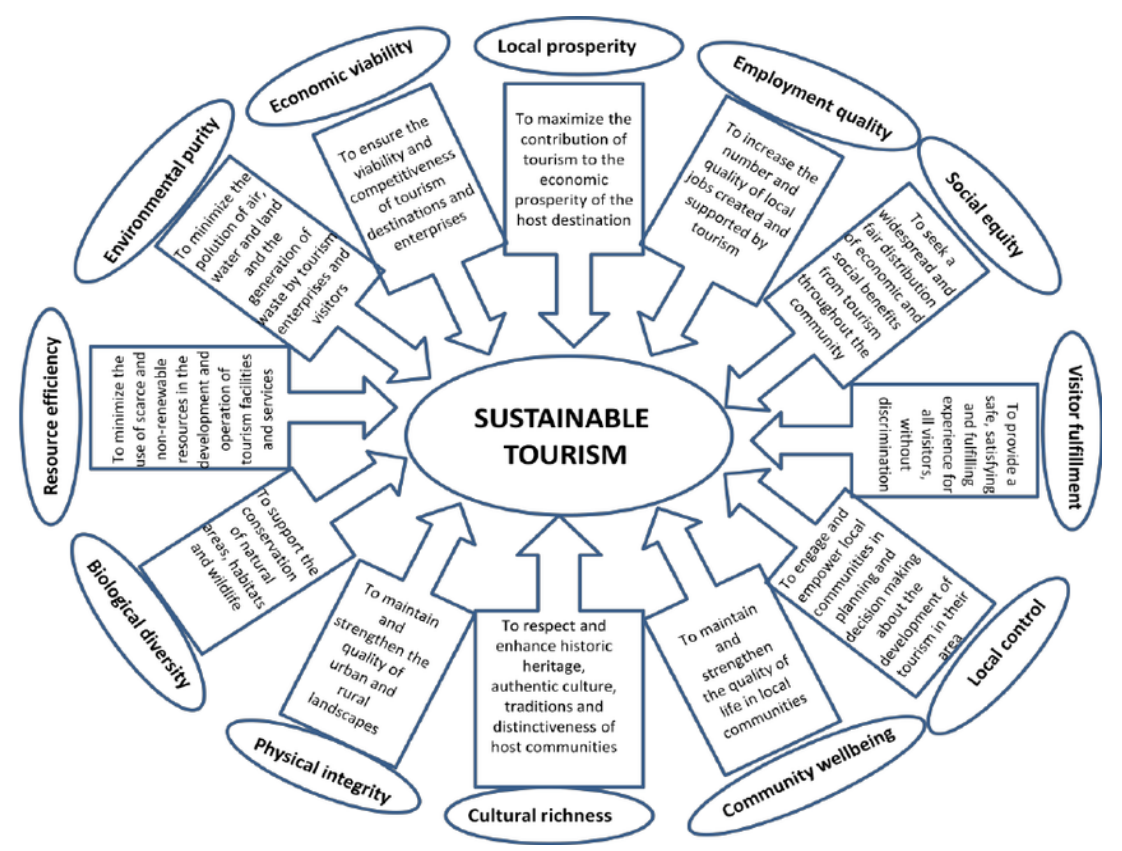

Fig. 1. Model of sustainable Tourism

Source: (UNTWO, 2005)[19]

Table 2. Review of sustainable tourism components

\begin{tabular}{|l|l|}
\hline \multicolumn{1}{|c|}{ Components } & \multicolumn{1}{c|}{ Deifications and Indicators } \\
\hline Economics & $\begin{array}{l}\text { Economic validity to ensure the validity and competiveness of tourism destination } \\
\text { and enterprise[19]. Increase the number and quality of local jobs created and } \\
\text { supported by tourism[19]. Long-term economic operations are ensured (providing } \\
\text { socio-economic benefits to all stakeholders that are fairly distributed[20]. }\end{array}$ \\
\hline Social & $\begin{array}{l}\text { The socio-cultural authenticity of host communities is respected (conserving built } \\
\text { and living cultural heritage and traditional values and contributing to inter-cultural } \\
\text { understanding and tolerance)[20]. To seek a wide spread and fair distribution of } \\
\text { social benefit from tourism throughout the community[19]. Engage and empower } \\
\text { local communities in planning and decision making about the development of } \\
\text { tourism in their area. Maintain and strengthen the quality of live in local commu- } \\
\text { nity. }\end{array}$ \\
\hline Environment & $\begin{array}{l}\text { Environmental resources are optimally used (maintaining essential ecological } \\
\text { processes and helping to conserve natural resources and biodiversity)[20]. Main- } \\
\text { tain and strengthen the quality of urban and rural landscapes[19]. Support the } \\
\text { conservation of natural areas, habitats and wildlife [19]. Minimize the use of } \\
\text { scarce and non-renewable resources in the development and operation of tourism } \\
\text { facilities and service, and to minimize the population of natural resources and the } \\
\text { generation of waste by tourism enterprise and visitors[19]. }\end{array}$ \\
\hline
\end{tabular}




\section{$3 \quad$ Methodology}

In order to come with framework and verifiable of SCT assessment process, this research consisted of the three stages outlined below.

\subsection{Literature reviews}

Review the existing definition, characteristics, and indicators based on creative tourism and sustainable tourism.

\subsection{Empirical investigation}

Empirical investigations involved in-depth interviews of five experts who currently work in the fields of creative tourism. The Indicators consisting of eight dimensions or components with 36 total indicators were developed by incorporating the existing concept from previous literatures with the results from our qualitative research that was conducted to improve these indicators. The question of an in-depth interview to improve indicators are as follows:

- What do you mean creative tourism?

- What do you think characteristics of creative tourism?

- What do you think component or indicator of sustainable creative tourism?

- What type of SCT assessment tools do you prefer to assess the creative tourism destination?

The interview structure was employed and each interview took approximately 1.01.5 hours. The respondents were asked to describe creative tourism implementation in the past, creative tourism management problem and sustainable challenge and also indicators for assessing SCT. The data were collected during November and December 2018. Purposive sampling was utilized for five participants. They included three from creative tourism entrepreneurs and two experts in the fields of SCT government agencies. Following are the sampling of interviewees

- The owner of cultural market "Talad Tainod" (www.facebook.com/Tainodgreenmarket)

- Community leader of floating market "Ampawa floating market" (en.wikipedia.org/wiki/Amphawa_Floating_Market)

- Leader of U Thong culture village (www.nationmultimedia.com/detail/thailand/30359609)

- Ex-ministry of Thailand tourism and sport

- Director of department of tourism.

The interview results were analyzed by content analysis, then SCT's dimensions and indicators are summarized to confirm the list of indicators, and then sent back to three of five participants to verify the Item Objective Congruence (IOC) with the eight components and 36 indicators. Table 3 shows the proposed SCT dimensions $(8$ 
components) with total indicators of 36 observed variables that were analyzed. The observed variables are also called indicator variables in this research. The eight dimensions of indicators are location (LCT), process (PRCS), management (MGT), creative tourism activity (CTA), knowledge management (KM), economics (ECON), social (SC), and environment (ENV).

Table 3. Proposed sustainable creative tourism dimensions and indicators

\begin{tabular}{|c|c|c|}
\hline Dimension & \begin{tabular}{c|}
$\begin{array}{c}\text { Indicator } \\
\text { Code }\end{array}$ \\
\end{tabular} & Definition of indicator \\
\hline \multirow{5}{*}{ Location } & LCT1 & $\begin{array}{l}\text { Creative tourism destination develops from cultural and/or natural / heritage } \\
\text { tourism. }\end{array}$ \\
\hline & LCT2 & Unique experience. \\
\hline & LCT3 & Interaction with cultural and environment. \\
\hline & LCT4 & Authentic experience. \\
\hline & LCT5 & Attractiveness of creativity as a form of expression. \\
\hline \multirow{5}{*}{ Process } & PRCS1 & Culture exchange. \\
\hline & PRCS2 & Ability to create authentic experience. \\
\hline & PRCS3 & Engaging with culture and heritage in local community. \\
\hline & PRCS4 & Process and activity to present meaning of cultural heritage. \\
\hline & PRCS5 & Make travelers satisfaction. \\
\hline \multirow{4}{*}{$\begin{array}{l}\text { Creative } \\
\text { tourism } \\
\text { activities }\end{array}$} & CTA1 & Interacting with people in community. \\
\hline & CTA2 & Local community desire for more active, engaging experiences with travellers. \\
\hline & CTA3 & Creative activity to present meaning of culture. \\
\hline & CTA4 & $\begin{array}{l}\text { Tourists able to learn more about the local skills, expertise, traditions and unique } \\
\text { qualities of the places they visited. }\end{array}$ \\
\hline \multirow{6}{*}{ Management } & MGT1 & Basic facility and infrastructure to support creative activity. \\
\hline & MGT2 & Time of activity. \\
\hline & MGT3 & Financial and cost management. \\
\hline & MGT4 & Promote invention / adoption new products / service from culture or heritage. \\
\hline & MGT5 & Stakeholder co: operation and community cooperation for social responsibility. \\
\hline & MGT6 & Strategic management, strategic plan, action plan, and evaluation. \\
\hline \multirow{4}{*}{$\begin{array}{l}\text { Knowledge } \\
\text { management }\end{array}$} & KM1 & Knowledge transfer and advisory with partnership. \\
\hline & KM2 & Learning with people, community, and culture. \\
\hline & KM3 & $\begin{array}{l}\text { Knowledge collected, stored, and educate to community and partnership to } \\
\text { conserve cultural heritage and traditional values. }\end{array}$ \\
\hline & KM4 & Combine and apply knowledge to new knowledge or new invention. \\
\hline \multirow{4}{*}{ Economics } & ECON1 & Create income to community / enterprise. \\
\hline & ECON2 & Increase income to community and long-term economic operations. \\
\hline & ECON3 & Increase the number and quality of local jobs. \\
\hline & ECON4 & Competitive attractiveness and tourism destination. \\
\hline \multirow{4}{*}{ Social } & $\mathrm{SC} 1$ & Engage and empower local communities in planning and decision making. \\
\hline & $\mathrm{SC} 3$ & Community wellbeing. \\
\hline & SC3 & Social equity / fair distribution of social benefit. \\
\hline & SC4 & Maintain and strengthen the quality of live in local community. \\
\hline \multirow{4}{*}{ Environment } & EVN1 & Minimize negative environment impact. \\
\hline & EVN2 & Environmental resources are optimally used. \\
\hline & EVN3 & Support the conservation of natural area, habitats and wildlife. \\
\hline & EVN4 & $\begin{array}{l}\text { Maintain essential ecological processes and helping to conserve natural re- } \\
\text { sources and biodiversity. }\end{array}$ \\
\hline
\end{tabular}




\subsection{Questionnaire validity and reliability}

After survey questionnaires verified by IOC, the survey questionnaire was justified to the eight dimensions with 36 observed variables with a five points likert scale. Then survey questionnaires were distributed to try out from 30 creative tourism enterprises. The questionnaire was validated for reliability by Cronbach's alpha coefficient. Testing the reliability of the present study, using Cronbach's alpha, it was found that the values of all Internal consistency were higher than 0.7 , so the participants' answers were considered to be reliable [21] (see Table 4).

Table 4. Cronbach's Alpha Coefficient for reliability analysis

\begin{tabular}{|l|c|c|}
\hline \multicolumn{1}{|c|}{ Dimension of SCT indicator } & $\begin{array}{c}\text { Number of indicators } \\
\text { Per each dimension }\end{array}$ & Internal Consistency \\
\hline Location & 5 & .706 \\
\hline Process & 5 & .888 \\
\hline Creative tourism activity & 4 & .796 \\
\hline Management & 6 & .876 \\
\hline Knowledge management & 4 & .893 \\
\hline Economics & 4 & .886 \\
\hline Social & 4 & .879 \\
\hline Environment & 4 & .924 \\
\hline
\end{tabular}

\section{$4 \quad$ Survey questionnaire}

Survey questionnaires of SCT indicators were distributed and collected from creative tourism enterprises during January and February 2019. The questionnaire was sent directly to participants who responded through an online survey by e-mail and direct mail to 300 creative tourism enterprises all around Thailand. The response rate was 253 participants which sufficient for CFA data analysis [21]. The CFA was used to calculate the component weight of the SCT.

\section{$5 \quad$ Finding}

This research used the AMOS software to test the CFA results. Data analytics using CFA of the SCT components and its observed variables. The measurement model fitness from CFA analysis is accepted (see Table 5.); $\chi^{2} / \mathrm{df}=2.07(\leq 5.00)$, CFI $=0.911 \quad(\geq 0.90), \quad$ TLI $=0.901 \quad(\geq 0.90), \quad$ RMSEA $=0.067 \quad(\leq 0.08)$, $\mathrm{SRMR}=0.048(\leq 0.08)$.

In addition, other condition such as the Convergent and Discriminant Validity and reliability of such model met the requirement of validity and reliability for the CFA. According to the finding, the 36 observed variables could achieve the assumption requirements that are the factor loading $\geq 0.5$ [22]. 
Table 5. Model fitness of CFA

\begin{tabular}{|l|l|l|l|}
\hline \multicolumn{1}{|c|}{ Category } & \multicolumn{1}{|c|}{ Level of Acceptance } & \multicolumn{1}{|c|}{ Model fitness } & \multicolumn{1}{c|}{ Result } \\
\hline AbsoluteF Fit Indices Relative Chi-square: $\chi^{2} / \mathrm{df}$ & $\chi 2 / \mathrm{df}<5.00[21]$ & 2.07 & Accept \\
\hline Comparative Fit Index: CFI) & CFI $>0.90[21]$ & 0.911 & Accept \\
\hline Trucker-Lewis Index (TLI) & TLI $>0.90[22]$ & 0.901 & Accept \\
\hline $\begin{array}{l}\text { Root Mean Square Error of Approximation: } \\
\text { RMSEA) }\end{array}$ & RMSEA $<0.08[22]$ & 0.067 & Accept \\
\hline Standardized Root Mean Square Residual: SRMR) & SRMR $<0.08[22]$ & 0.048 & Accept \\
\hline
\end{tabular}

Table 6. Convergent validity

\begin{tabular}{|c|c|c|c|c|}
\hline Components & Indicators & Factor Loading & $\begin{array}{l}\text { Average Variance } \\
\text { Extracted (AVE) }\end{array}$ & $\begin{array}{c}\text { Construct Relia- } \\
\text { bility (CR) }\end{array}$ \\
\hline \multicolumn{2}{|c|}{ Location } & & 0.509 & 0.838 \\
\hline & LCT1 & 0.632 & & \\
\hline & LCT2 & 0.731 & & \\
\hline & LCT3 & 0.761 & & \\
\hline & LCT4 & 0.693 & & \\
\hline & LCT5 & 0.745 & & \\
\hline \multicolumn{2}{|c|}{ Process } & & 0.645 & 0.900 \\
\hline & PRCS1 & 0.774 & & \\
\hline & PRCS2 & 0.824 & & \\
\hline & PRCS3 & 0.832 & & \\
\hline & PRCS4 & 0.813 & & \\
\hline & PRCS5 & 0.772 & & \\
\hline Creative to & ism activity & & 0.634 & 0.873 \\
\hline & CTA1 & 0.730 & & \\
\hline & CTA2 & 0.761 & & \\
\hline & CTA3 & 0.850 & & \\
\hline & CTA4 & 0.838 & & \\
\hline $\operatorname{Man}$ & ement & & 0.557 & 0.883 \\
\hline & MGT1 & 0.739 & & \\
\hline & MGT2 & 0.779 & & \\
\hline & MGT3 & 0.738 & & \\
\hline & MGT4 & 0.749 & & \\
\hline & MGT5 & 0.740 & & \\
\hline & MGT6 & 0.730 & & \\
\hline Knowledge & tanagement & & 0.721 & 0.912 \\
\hline & KM1 & 0.848 & & \\
\hline & KM2 & 0.901 & & \\
\hline & KM3 & 0.819 & & \\
\hline & KM4 & 0.826 & & \\
\hline Eco & mics & & 0.964 & 0.901 \\
\hline & ECON1 & 0.829 & & \\
\hline & ECON2 & 0.883 & & \\
\hline & ECON3 & 0.813 & & \\
\hline & ECON4 & 0.829 & & \\
\hline & ial & & 0.637 & 0.875 \\
\hline & $\mathrm{SC} 1$ & 0.775 & & \\
\hline & $\mathrm{SC} 3$ & 0.892 & & \\
\hline
\end{tabular}


Paper-Development of Mobile Application for Sustainable Creative Tourism Assessment using ...

\begin{tabular}{|c|l|c|c|c|}
\hline Components & \multicolumn{1}{|c|}{ Indicators } & Factor Loading & $\begin{array}{c}\text { Average Variance } \\
\text { Extracted (AVE) }\end{array}$ & $\begin{array}{c}\text { Construct Relia- } \\
\text { bility (CR) }\end{array}$ \\
\hline & SC3 & 0.735 & & \\
\hline & SC4 & 0.783 & & 0.877 \\
\hline \multicolumn{2}{|c|}{ Environment } & & 0.642 & \\
\hline & EVN1 & 0.725 & & \\
\hline & EVN2 & 0.893 & & \\
\hline & EVN3 & 0.848 & & \\
\hline & EVN4 & 0.724 & & \\
\hline
\end{tabular}

This research proposed the SCT indicator model as shown in figure 2, which was constructed from eight dimensions with 36 observed indicators. There is no multicollinearity and validity issue found. The CFA finding shows there is no issue on the validity and reliability of each data. The model constructs finding of validity and reliability and the Discriminant Convergent as a whole are meeting all the condition of the validity and reliability of CFA, so that SCT model able to use evaluate and assess sustainable creative tourism.

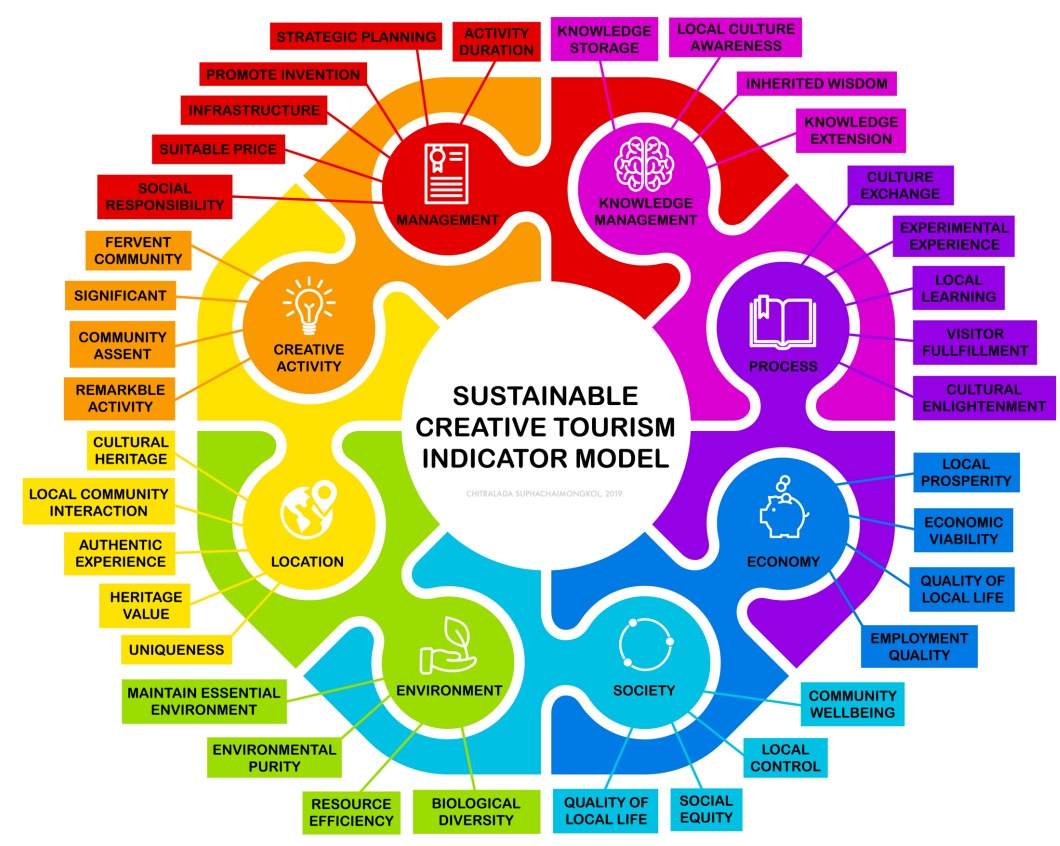

Fig. 2. Proposed Sustainable Creative Tourism Indicator Model 


\section{Development of Mobile Application for SCT assessment}

This research also aims to develop the prototype of mobile application to assess creative tourism destination. In-depth interviewed from experts and creative tourism enterprises found that most of them need tool to assess creative tourism in forms of mobile application [23] and/or web-based that are also able to support various type of users such as creative tourism entrepreneur, community leaders, tourist, consultant, and government agencies. The system also should be able to support many levels of users such as individual, group community, and region level and also should be able to compare with others creative tourism destinations.

The mobile application prototype of SCT was developed, based on eight dimensions with 36 indicators. System users are divided in to four main groups (see Figure 2) are 1) entrepreneur in creative tourism destination, 2) creative tourism administrators, 3) Tourist or traveler, and 4) Government agencies.
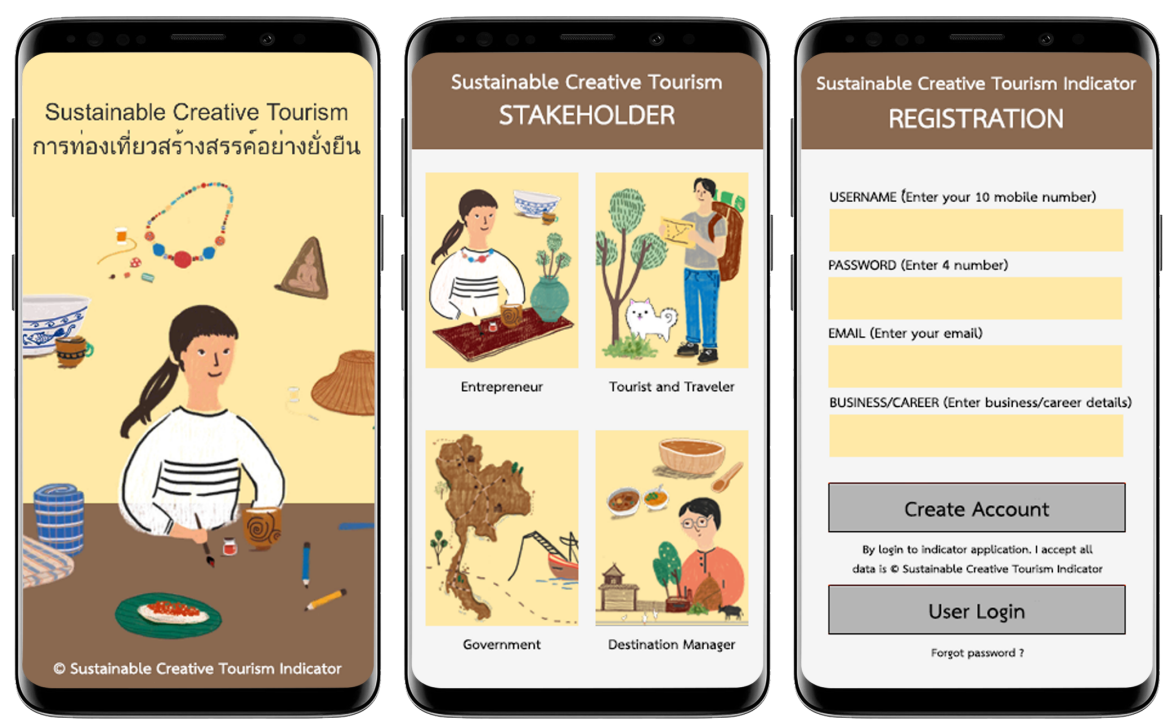

Fig. 3. SCT assessment mobile application user interface

The SCT mobile application allows user (entrepreneur and tourist/travelers) to assess their own private destination [24], then destination manager and government agencies able to access to view assessment result in each component via mobile application and also able to compare with others creative tourism destination (see Figure $3)$. 


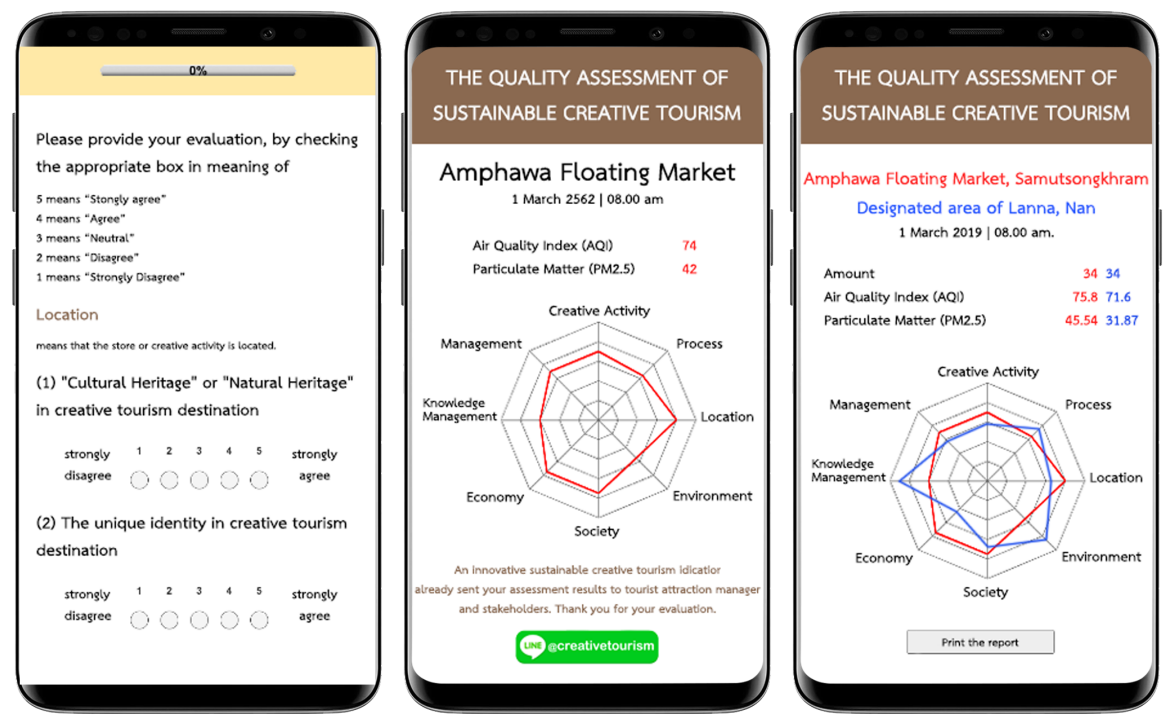

Fig. 4. SCT assessment indicators

\section{Conclusion}

This research introduces the process development of the mobile application assessment tool for sustainable creative tourism from empirical statistic study using CFA approach. The study was divided into 4 phases are 1) Construct the research framework based on literature review and the opinions of experts, 2) Select components and indicators by using Delphi technique from 30 samples. 3) SCT's dimensions and indicators were confirmed by utilizing CFA from 253 samples. The finding found on the validity and reliability test of the SCT model which involved CFA are represented the observed variables (indicators) studied. Meanwhile, it is also confirmed the theorized of CFA use in this study, or the theories fit the data. Therefore, it is confirmed that 8 components and 36 indicators of SCT model able to use for creative tourism assessment. Finally, the prototype of SCT mobile application was implemented based on CFA indicators analytics. The SCT mobile application prototype can support 4 types of users are entrepreneur in creative tourism destination, creative tourism administrators, tourist or travelers, and government agencies. The future study we suggest to study on other components and its' indicators (extension model) based on specific location or service of creative tourism destinations. We also suggest to study on users' satisfaction of SCT mobile application, and technology acceptance from SCT assessment tool. 


\section{Acknowledgement}

Authors would like to express thanks and appreciation to the creative tourism entrepreneurs from all around Thailand to gives respond questionnaires for this research study. We also would like to thank the Technopreneurship and Innovation Management Programme, Graduate School, Chulalongkorn University, Thailand for supporting this research study.

This research work has been funded by "Office of the Higher Education Commission" and "Research and Researchers for Industries" Bangkok, Thailand.

\section{References}

[1] G. Richards and L. Marques, "Exploring creative tourism: Introduction," Transfusion, vol. 4, no. 2, pp. 1-11, 2012.

[2] UNESCO, "Towards Sustainable Strategies for Creative Tourism," ed: UNESCO, 2006.

[3] I. Tiyaphipat, "Basic of Creative Tourism," presented at the Proceedings of 49th IASTEM International Conference, San Francisco, USA., 20th-21st March 2017, 2017.

[4] S. K. Tan, F. S. Kung, and B. D. Luh, "A model of "Creative Experience" in Creative Tourism," Annals of Tourism Research, vol. 41, pp. 153-174, 2013. https://doi.org/10.1016/j.annals.2012.12.002

[5] C. Alberto Scolari and J. Fernandez-Cavia, "Mobile Applications and Destination Branding in Spain," International Journal of Interactive Mobile Technologies (iJIM), vol. 8, no. 2, pp. 15-22, 2014. https://doi.org/10.3991/ijim.v8i2.3575

[6] Suddan Wisudthiluck, Pichet Saiphan, Ornuma Teparakul, and Teera Sindecharak, "Creative Tourism Achievement in Thailand: Evaluated by Experts and Tourists," Thammasat Review, vol. 19, no. 1, pp. 75-87, 2016.

[7] R. Ohridska-Olson and S. Ivanov, "Creative Tourism Business Model And Its Application In Bulgaria," in Proceedings of the Black Sea Tourism Forum 'Cultural Tourism - The Future of Bulgaria,' 2010, Bulgaria, 2010: Varna University of Management. https://doi.org/10.1007/978-3-319-01669-6 345-1

[8] F. Doosti, M. Hassan Zaal, and R. M. Lasbuie, "Factors Involved in Assessing Capacity of Creative Tourism: Case Study - Tabriz City in Iran," Journal of Tourism \& Hospitality, vol. 6, no. 6, pp. 2-11, 2017. https://doi.org/10.4172/2167-0269.1000332

[9] F. Luangchanduang and P. Waraporn, "Development of sustainable Creative indicators for Community based Tourism," Electronic Journal of Open Distance Innovation Learning, vol. 8, no. 1, 2018.

[10] C. Raymond, "Creative tourism New Zealand," in Tourism, Creativity and Development G. Richards, \& Wilson, J., Ed. London: Routledge, 2007.

[11] G. Richards and C. Raymond, "Creative Tourism," ATLAS news, vol. 23, pp. 12-60, 2000.

[12] R. Wurzburger, T. Aegeson, A. Pattekos, and S. Pratt, "reative Tourism: A Global Conversation: How to Provide Unique Creative Experiences for Travelers Worldwide.," presented at the 2008 Santa Fe and UNESCO International Conference on Creative Tourism, Santa Fe, New Mexico, USA, 2009. https://doi.org/10.7202/1038828ar

[13] DASTA, "Definition of 'Creative Tourism'," ed: Designated Areas for Sustainable Tourism Administration 2013.

[14] G. Richards and J. Wilson, From cultural tourism to creative tourism. ATLAS, 2008. 
Paper-Development of Mobile Application for Sustainable Creative Tourism Assessment using ...

[15] G. Richards, "Creativity and Tourism: The state of the Art," Annals of Tourism Research, vol. 38, no. 4, pp. 1225-1253, 2011. https://doi.org/10.1016/j.annals.2011.07.008

[16] G. Richards, "Creative Tourism and Local Development," in Creative Tourism: A global conversation., R. Wurzburger, A. Pattakos, and S. Pratt, Eds. Santa Fe: Sunstone Press, 2009, pp. 78-90. https://doi.org/10.7202/1038828ar

[17] R. Florida, The Rise of the creative class: and how it's transforming work, leisure, community and everyday life. . NewYork, : Basic Books, 2002. https://doi.org/10.25071/17051436.180

[18] A. Urtasun and I. Gutiérrez, "ourism agglomeration and its impact on social welfare: An empirical approach to the Spanish case.," Tourism Management, vol. 27, pp. 901-912, 2006. https://doi.org/10.1016/j.tourman.2005.05.004

[19] UNWTO, "Making Tourism More Sustainable - A Guide for Policy Makers,," pp. 1112Available:http://sdt.unwto.org/content/about-us-5. https://doi.org/10.18111/9789284408214

[20] R. Korez-Vide, "Promoting Sustainability of Tourism by Creative Tourism Development : How Far is Slovania? ," Innovative Issues and Approaches in Social Sciences, vol. 6, no. 1, pp. 77-102, 2013. https://doi.org/10.12959/issn.1855-0541.iiass-2013-no1-art05

[21] J. F. Hair, W. C. Black, B. J. Babin, and R. E. Anderson, Multivariate Data Analysis. Upper Saddle River, New Jersey.: Prentice Hall, 2010.

[22] M. P. Bentler, "Comparative Fit Indexes in Structural Models," Psychological Bulletin, vol. 107, no. 2, pp. 238-246, 1990. https://doi.org/10.1037//0033-2909.107.2.238

[23] M. Aitkenhead, D. Donnelly, M. Coull, and E. Hastings, "Innovations in Environmental Monitoring Using Mobile Phone Technology - A Review," International Journal of Interactive Mobile Technologies (iJIM), vol. 8, no. 2, pp. 42-50, 2014. https://doi.org/10.3991/ijim.v8i2.3645

[24] B. Jagdale and J. Bakal, "Privacy Aware Monitoring of Mobile Users in Sensor Networks Environment," International Journal of Interactive Mobile Technologies (iJIM), vol. 13, no. 2, pp. 127-140, 2019. https://doi.org/10.3991/ijim.v13i02.10023

\section{Authors}

Chitralada Suphachaimongkol is doctor of philosophy candidate at the Department of Technopreneurship and Innovation Management, Graduate School, Chulalongkorn University, Bangkok, Thailand. (e-mail: chsuph@gmail.com)

Chavalit Ratanatamskul is associate professor at the Department of Environmental Engineering, Faculty of Engineering, Chulalongkorn University, Bangkok, Thailand.

Siriwan Silapacharanan is professor emeritus at the Department of Urban and Regional Planning, Faculty of Architecture, Chulalongkorn University, Bangkok, Thailand.

Patcha Utiswannakul is associate professor at the Department of Creative Arts, Faculty of Fine and Applied Arts, Chulalongkorn University, Bangkok, Thailand.

Article submitted 2019-03-18. Resubmitted 2019-04-24. Final acceptance 2019-04-24. Final version published as submitted by the authors. 